\title{
Extended State Observer-based Vector Control for PMSM Drive System with Single Phase Current Sensor
}

\author{
Qingfang Teng ${ }^{1}$, Hongwei Cui ${ }^{1}$, Junyi Duan ${ }^{2}$, Jianguo Zhu ${ }^{3}$, Youguang $\mathrm{Guo}^{3}$, and Gang Lei ${ }^{3}$ \\ ${ }^{1}$ Department of Automation and Electrical Engineering, Lanzhou Jiaotong University, Lanzhou Gansu 730070, China \\ ${ }^{2}$ Graduate Management Team Department, Engineering University of Armed Police Force, Xi'an Shaanxi 710000, China \\ ${ }^{3}$ Faculty of Engineering and Information Technology, University of Technology, Sydney, 2007, Australia \\ Email: tengqf@mail.lzjtu.cn
}

\begin{abstract}
A novel extended state observer (ESO)-based vector control (VC) strategy is developed for permanent magnet synchronous motor (PMSM) drive systems with only one phase current sensor. Generally, to achieve high precision control, two phase current sensors are indispensable for successful operation of the feedback control. In response to a phase current sensor fault, by use of technique of ESO, a new observer for estimating both the remaining two phase currents and time-varying stator resistance is put forward. To improve the performance and decrease system high frequency vibration, a nonlinear exponential function is used to replace the switch function in conventional ESO. The resultant ESO-based VC strategy for PMSM drive system with single phase current sensor has strong robustness and satisfactory control performance. Numerical simulation validates the feasibility and effectiveness of the proposed scheme.
\end{abstract}

Index Terms-- Extended state observer, PMSM drive system, Single phase current sensor, Vector control.

\section{INTRODUCTION}

For PMSM drive system, the measurement of instantaneous stator currents is required for successful operation of the feedback control. Generally two phase current sensors are installed in three phase voltage source inverters (VSI). Nevertheless, sudden severe failure of phase current sensors would result in over-current malfunction of the drive system. And if there is no protection scheme in the gate-drive circuit, the failure would lead to irrecoverable fault of power semiconductors in VSI, which causes degradation of motor drive performance. Additionally, some minor failures (such as gain drift and nonzero offset) of phase current sensors would lead to torque pulsation synchronizing with the inverter output frequency [1]. The larger offset and scaling error of phase current sensors would bring about the worse performance of torque regulation. Moreover, if the offset and gain drift are above some certain level, it would cause over-current trip under high speed and heavy load conditions [2]. So it is necessary to consider fault tolerant operation of phase current sensor failure.

As far as the current sensorless technique, which is regarded as fault tolerant one, is concerned, two methods have been reported in the literature. The first is the DC-

This work was supported by National Natural Science Foundation of China (61463025). link current-based approach [3]-[4]. Although it is mainstream method, its unavoidable drawbacks are exposed: the duration of an active switching state is so short that the DC-link current cannot be measured, meanwhile, there are immeasurable regions in the output voltage hexagon where the DC-link current sampling is limited or impossible to do. In order to obtain high precision reconstruction current, many kinds of improved DC-link current reconstruction methods based on PWM modulation strategy are proposed [5]-[10]. Although these studies improved the accuracy of phase current estimation, but the algorithm is complex. Moreover, vector control of PMSM drives based on single phase current is given in the literature [11], in which an isolated current sensor is used instead of DC bus current sensor and a new method of three-phase currents reconstruction based on zero voltage vector sampling is proposed. However, the single current sensor sampled twice in each PWM cycle, therefore the dynamic performance of current control is deteriorated [12].The second is an adaptive observer-based approach [13]-[14]. Their limitation is that the stator resistance change is assumed to be slow.

In addition to two methods mentioned above, a new extended state observer (ESO)-based method is applied. By extending unknown variable as an incremental state of the original system, ESO can estimate the unknown varia ble without requiring much model information. As a result, ESO technique will be introduced into PMSM phase current estimation. To improve the performance and decrease system chattering, a nonlinear exponential function (NEF) is used to replace the switch function in conventional ESO. Compared with the first two methods, the NEF-based ESO proposed by this paper has no limitation for applicable scope and constraint condition. Moreover, its operation process is not complicated and algorithm execution is easy. So far there is no literature on such observer.

\section{DYNAMIC MODEL OF PMSM DRIVE}

As for three-phase PMSM drive, the models in rotor synchronous reference frame ( $d q$-frame) and two-phase stationary reference frame ( $\alpha \beta$-frame) are expressed as follows, respectively, 


$$
\begin{aligned}
& \left\{\begin{array}{l}
\frac{\mathrm{d} i_{d}}{\mathrm{~d} t}=\frac{1}{L_{d}}\left(u_{d}-R_{s} i_{d}+\mathrm{p} \omega_{r} L_{q} i_{q}\right) \\
\frac{\mathrm{d} i_{q}}{\mathrm{~d} t}=\frac{1}{L_{q}}\left(u_{q}-R_{s} i_{q}-\mathrm{p} \omega_{r}\left(L_{d} i_{d}+\psi_{m}\right)\right)
\end{array}\right. \\
& \left\{\begin{array}{l}
\frac{\mathrm{d} i_{\alpha}}{\mathrm{d} t}=\frac{1}{L_{\alpha}}\left(u_{\alpha}-R_{s} i_{\alpha}+\mathrm{p} \omega_{r} \psi_{m} \sin \theta_{e}\right) \\
\frac{\mathrm{d} i_{\beta}}{\mathrm{d} t}=\frac{1}{L_{\beta}}\left(u_{\beta}-R_{s} i_{\beta}-\mathrm{p} \omega_{r} \psi_{m} \cos \theta_{e}\right)
\end{array}\right.
\end{aligned}
$$

where $R_{\mathrm{s}}$ is stator resistance. $L_{\mathrm{d}}, L_{\mathrm{q}}, u_{\mathrm{d}}, u_{\mathrm{q}}$ and $i_{\mathrm{d}}, i_{\mathrm{q}}$ are dq-axes stator inductances, voltages and currents, respectively. $L_{\alpha}, L_{\beta}, u_{\alpha}, u_{\beta}$ and $i_{\alpha}, i_{\beta}$ are $\alpha \beta$-axes stator inductances, voltages and currents, respectively. $\psi_{\mathrm{m}}$ is permanent magnet flux. $\omega_{\mathrm{r}}$ is rotor mechanical speed. $p$ is the number of pole pairs. $\theta_{\mathrm{r}}$ and $\theta_{\mathrm{e}}$ are rotor mechanical and electrical positions, respectively, and $\theta_{\mathrm{e}}=p \theta_{\mathrm{r}}$.

And mechanical equation is expressed as

$$
\frac{\mathrm{d} \omega_{r}}{\mathrm{~d} t}=\frac{1}{J}\left(T_{e}-T_{l}-B \omega_{r}-T_{f}\right)
$$

where $J$ is moment of inertia. $T_{1}$ and $T_{\mathrm{f}}$ are load torque and coulomb friction torques, respectively. $B$ is viscous friction coefficient. $T_{\mathrm{e}}$ is electromagnetic torque which is expressed as

$$
T_{e}=\frac{3 \mathrm{p}}{2}\left[\psi_{m} i_{q}+\left(L_{d}-L_{q}\right) i_{d} i_{q}\right]
$$

\section{DESIGN OF ESO-BASED VECTOR CONTROL FOR PMSM DRIVE SYSTEM WITH SINGLE PHASE CURRENT SENSOR}

The objective of ESO-based VC is that PMSM drive system can work reliably and its speed and torque can be controlled to have satisfactory performance. The schematic of the proposed control system is shown in Fig.1. Our task concentrates on ESO design.

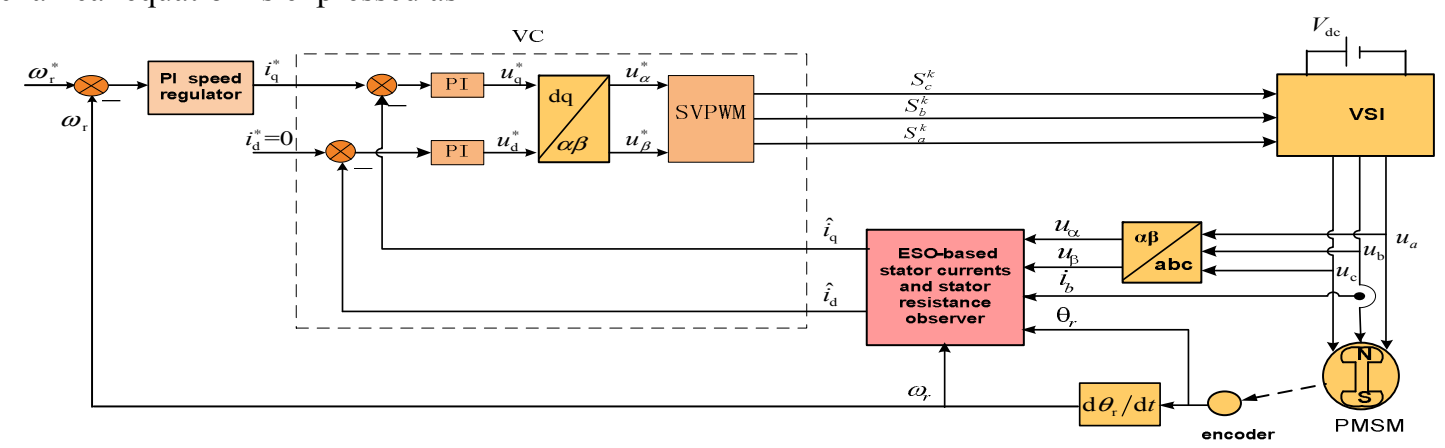

Fig. 1. Block diagram of ESO-based VC PMSM drive system

The proposed ESO is to estimate the remaining two phase currents and time-varying stator resistance when single phase current sensor is available. In the design process, following assumptions are considered

- Only phase- $b$ stator current can be measured and remaining two phase currents sensors are not available.

- Due to heating during operating of motor, stator resistance $R_{S}$ is time-variant.

- There is no saturation in the magnetic circuit.

For surface-mounted PMSM drive, $L_{d}=L_{q}=L_{\alpha}=L_{\beta}=L$. The $\alpha$-axis in $\alpha \beta$-frame is oriented along phase- $a$ axis in three-phase stationary reference frame ( $a b c$-frame). The $a b c$-axes stator currents in $a b c$-frame can be obtained from $\alpha \beta$-axes ones in $\alpha \beta$-frame by following transformation matrix

$$
\left[\begin{array}{l}
i_{a} \\
i_{b} \\
i_{c}
\end{array}\right]=\left[\begin{array}{cc}
1 & 0 \\
-1 / 2 & \sqrt{3} / 2 \\
-1 / 2 & -\sqrt{3} / 2
\end{array}\right]\left[\begin{array}{l}
i_{\alpha} \\
i_{\beta}
\end{array}\right]
$$

where $i_{a}, i_{b}$ and $i_{c}$ are $a b c$-axes stator currents in $a b c$ frame. From (5), following equation can be given,

$$
i_{b}=-\frac{1}{2} i_{\alpha}+\frac{\sqrt{3}}{2} i_{\beta}
$$

Taking (2) into account, the derivative of (6) is deduced as follows

$$
\begin{aligned}
\frac{\mathrm{d} i_{b}}{\mathrm{~d} t}= & \frac{\sqrt{3}}{2 L}\left[u_{\beta}-R_{s}\left(\frac{1}{\sqrt{3}} i_{\alpha}+\frac{2}{\sqrt{3}} i_{b}\right)-\mathrm{p} \omega_{r} \psi_{\mathrm{m}} \cos \theta_{e}\right]- \\
& \frac{1}{2 L}\left(u_{\alpha}-R_{s} i_{\alpha}+\mathrm{p} \omega_{r} \psi_{\mathrm{m}} \sin \theta_{e}\right) \\
= & \frac{\sqrt{3} u_{\beta}-u_{\alpha}-2 R_{s} i_{b}-\mathrm{p} \omega_{r} \psi_{\mathrm{m}}\left(\sqrt{3} \cos \theta_{e}+\sin \theta_{e}\right)}{2 L}
\end{aligned}
$$

Suppose $x_{1}=i_{b}$

And define

$$
\begin{aligned}
& u=\frac{1}{2 L}\left[\begin{array}{llll}
u_{\alpha} & u_{\beta} & \psi_{m} \omega_{e} \sin \theta_{e} & \psi_{m} \omega_{e} \cos \theta_{e}
\end{array}\right]^{\mathrm{T}} \\
& \mathrm{B}=\left[\begin{array}{llll}
-1 & \sqrt{3} & -1 & -\sqrt{3}
\end{array}\right]
\end{aligned}
$$

Thus state space equation of (7) can be expressed as

$$
\left\{\begin{array}{l}
\dot{x}_{1}=-\frac{1}{L} R_{s} x_{1}+\mathrm{Bu} \\
y=x_{1}
\end{array}\right.
$$

where $u$ and $y$ can be regarded as the input and output of (10), and $B$ is input matrix.

Because the stator resistance $R_{s}$ is time-varying, $R_{\mathrm{S}} x_{1}$ in (10) is unknown. Therefore, $R_{\mathrm{s}} x_{1}$ can be extended as a new state $x_{2}$, i.e.,

Let

$$
x_{2}=R_{s} x_{1}
$$

$$
q(t)=\dot{x}_{2}
$$

Taking (11) into account, (12) can be rewritten as

$$
q(t)=\dot{R}_{s} x_{1}+R_{s} \dot{x}_{1}=\dot{R}_{s} i_{b}+R_{s} \dot{i}_{b}
$$


Because $\dot{i}_{b}$ and $\dot{R}_{s}$ are bounded, $q(\mathrm{t})$ is also bounded, i.e.,

$$
|q(t)|<q_{0}
$$

Where $q_{0}$ is a positive real number.

Then the extended state space equation of (10) can be expressed as

$$
\left\{\begin{array}{l}
\dot{x}_{1}=-x_{2} / L+\mathrm{Bu} \\
\dot{x}_{2}=q(t) \\
y=x_{1}
\end{array}\right.
$$

(15) is observable, so its second-order ESO can be constructed as

$$
\left\{\begin{array}{l}
e=w_{1}-x_{1} \\
\dot{w}_{1}=-\frac{1}{L} w_{2}+\mathrm{Bu}-\beta_{1} e \\
\dot{w}_{2}=-\beta_{2}|e|^{\alpha} \operatorname{sign}(e)
\end{array}\right.
$$

In fact, (16) is a conventional ESO, of which $\operatorname{sign}(\cdot)$ is a switch function. In order to avoid high frequency vibration caused by the switch function and improve performance, a nonlinear exponential function is used to replace the switch function and thus NEF-based ESO is

$$
\left\{\begin{array}{l}
e=w_{1}-x \\
\dot{w}_{1}=-\frac{1}{L} w_{2}+\mathrm{Bu}-\beta_{1} e \\
\dot{w}_{2}=-\beta_{2} \text { fal }(e, \alpha, \delta)
\end{array}\right.
$$

where $\beta_{1}$ and $\beta_{2}$ are positive observer gains, $\alpha$ and $\delta$ are positive parameters, $f a l(e, \alpha, \delta)$ is a nonlinear function which is defined as

$$
\text { In (17) }
$$$$
f a l(e, a, \delta)= \begin{cases}\frac{e}{\delta^{1-a}}, & |e| \leq \delta \\ \operatorname{sign}(e) \cdot|e|^{a}, & |e|>\delta\end{cases}
$$

$$
w_{1}=\hat{x}_{1}, w_{2}=\hat{x}_{2}=\hat{x}_{1} \hat{R}_{s}
$$

where $\hat{x}_{1}$ and $\hat{x}_{2}$ are the estimated values of $x_{1}$ and $x_{2}$, respectively.

From (19), the estimated value of $R_{\mathrm{s}}$ can be obtained as

$$
\hat{R}_{\mathrm{s}}=w_{2} / w_{1}
$$

By replacing $R_{s}$ in (1) with $\hat{R}_{s}$ in (20), the observer of $d q$-axes currents can be constructed as follows

$$
\left\{\begin{array}{l}
\frac{\mathrm{d} \hat{i}_{d}}{\mathrm{~d} t}=\frac{1}{L}\left(u_{d}-\hat{R}_{s} \hat{i}_{d}+\mathrm{p} \omega_{r} L \hat{i}_{q}\right) \\
\frac{\mathrm{d} \hat{i}_{q}}{\mathrm{~d} t}=\frac{1}{L}\left(u_{q}-\hat{R}_{s} \hat{i}_{q}-\mathrm{p} \omega_{r}\left(L \hat{i}_{d}+\psi_{m}\right)\right)
\end{array}\right.
$$

In line according with [15], if the following inequality holds

$$
\beta_{1}^{2} / 4>\beta_{2}>q_{0}
$$

The NEF-based ESO (17) is stable, which can ensure that $w_{1}$ and $w_{2}$ quickly converges to $x_{1}$ and $x_{2}$, respectively, thereby $\hat{R}_{s}$ converges to actual value $R_{s}$ and then $\hat{i}_{\alpha}$ and $\hat{i}_{\beta}$ also quickly track their actual value $i_{\alpha}$ and $i_{\beta}$, respectively.

By combining (17), (20) and (21), the block diagram of the designed ESO observer is established as shown in Fig. 2 , which treats stator voltages, rotor angular position and speed as inputs, $d q$-axes currents as outputs when only phase- $b$ current is measured.

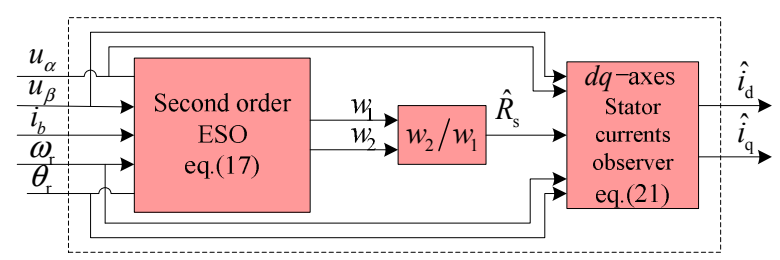

Fig. 2. ESO-based stator currents and stator resistance observer

As for the NEF-based ESO design, there are several remarks as following

- From Fig. 2, it can be seen that although phase- $b$ stator current can be measured, it is needed to be estimated, which is a key step and primary premise in construction of the ESO (17). The error between the phase- $b$ measured current and its estimated value must be guaranted to converge to zero.

- General principle of the parameter selection ${ }^{[15]-[17]}$ of ESO (17) is

(1) $0<\alpha \leq 1$.

(2) $\delta$ indicates the width of the linear interval near the original point, to which system steady state error relates. $\delta$ is selected from [0.0001 1]. When $\delta$ is less than 0.0025 , it is easy to cause system high frequency pulsation. On the other hand, when $\delta$ is too large, the effect of nonlinear feedback control can not be achieved. In practical application, it is generally selected to be 0.01 .

(3) $\beta_{i}(i=1,2)$ can be determined on the basis of system tracking performance. The large $\beta_{i}$ is helpful to increase tracking speed, however, it will lead to system oscillation and overshoot. In general, the value of $\beta_{1}$ is larger than $1 \sim 2$ orders of $\beta_{2}$. There is a compromise between $\beta_{i}(i=1,2)$ and $\delta$ for a better noise suppression and tracking performance.

- The estimated $d q$-axes currents in Fig.2 will be applied to VC as shown in Fig.1.

- From (5), the estimation of phase- $a$ current in $a b c$ frame is equal to that of $\alpha$-axis current in $\alpha \beta$-frame as follows

$$
\hat{i}_{a}=\hat{i}_{\alpha}
$$

Accordingly, the estimation of phase-c current in $a b c$-frame can be obtained as follows

$$
\hat{i_{c}}=-\left(i_{b}+\hat{i}_{\alpha}\right)
$$

\section{SIMULATION RESUlT AND ANALYSIS}

In order to validate the effective of proposed control strategy, the designed control system as shown in Fig.1 
has been implemented in Matlab/Simulink/Simscape platform. The parameters of PMSM are given in Table 1.

TABLE I PARAMETERS OF PMSM

\begin{tabular}{|c|c||c|c|}
\hline Symbol & Value & Symbol & Value \\
\hline $\mathrm{R}_{\mathrm{s}}$ & $2.875 \Omega$ & $T_{n}$ & 4 N.m \\
$L_{\mathrm{d}}, L_{\mathrm{q}}$ & $0.0085 \mathrm{H}$ & $n_{N}$ & $2000 \mathrm{rpm}$ \\
$\Psi_{\mathrm{f}}$ & $0.175 \mathrm{~Wb}$ & $J$ & $0.0008 \mathrm{Kg} \cdot \mathrm{m}^{2}$ \\
$\mathrm{p}$ & 4 & $B_{m}$ & $0.001 \mathrm{~N} . \mathrm{m} . \mathrm{s}$ \\
$V_{D C(\text { nom })}$ & $300 \mathrm{~V}$ & $T_{f}$ & 0 \\
\hline
\end{tabular}

The sampling period is $26 \mu$ s. The reference $d$-axis current $i_{d}{ }^{*}$ is $0 \mathrm{~A}$. The parameters of the ESO (17) are

$$
\delta=0.01, \quad \alpha=0.1, \quad \beta_{1}=6100, \quad \beta_{2}=128580
$$

The parameters of PI speed regulator in Fig. 1 are

$$
k_{P}=0.4, \quad k_{\mathrm{i}}=0.1
$$

The parameters of $q$-axis PI of VC in Fig. 1 are

$$
k_{P}=40, k_{\mathrm{i}}=5
$$

The parameters of $d$-axis PI of $\mathrm{VC}$ in Fig. 1 are

$$
k_{P}=20, k_{\mathrm{i}}=0.01
$$

\section{A. Dynamic response under the variation of stator resistance}

Here, the stator resistance is changed from its nominal value $2.875 \Omega$ to $3.5 \Omega$ at 0.3 seconds. Fig. 3 shows dynamic responses in terms of stator currents, stator resistance, rotor speed and torque when reference speed $\mathrm{n}^{*}$ is set to $1000 \mathrm{rpm}$, the load torque is $2 \mathrm{~N} \cdot \mathrm{m}$.

From Figs.3(a)-3(c), it can be seen that, for the designed ESO, the estimated $a$-axis and $c$-axis currents in $a b c$-frame rapidly track their actual value, and the estimated stator resistance can rapidly follow its actual resistance change and converge to its actual value accurately. Figs. 3(d)-3(e) show that its speed and torque have strong immunity to stator resistance change, and the proposed ESO-based VC system has satisfactory control performance.

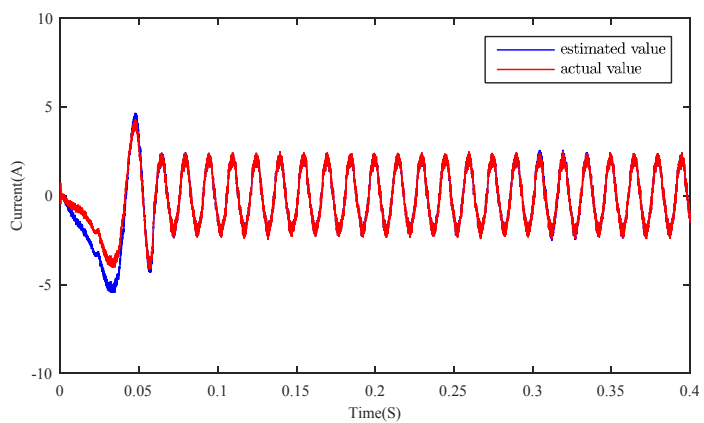

(a) $a$-axis stator current in $a b c$-frame

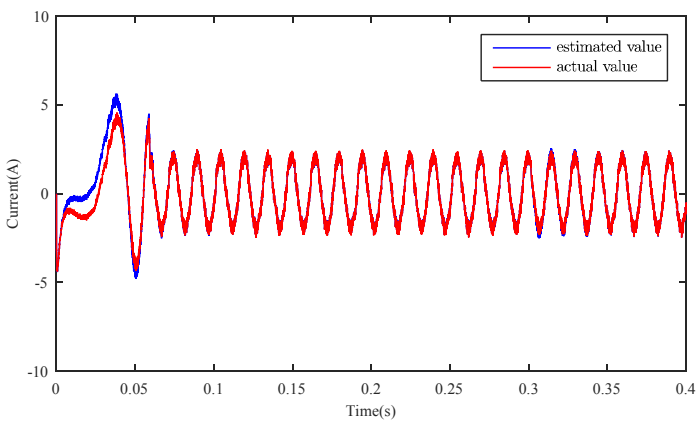

(b) $c$-axis stator current in $a b c$-frame

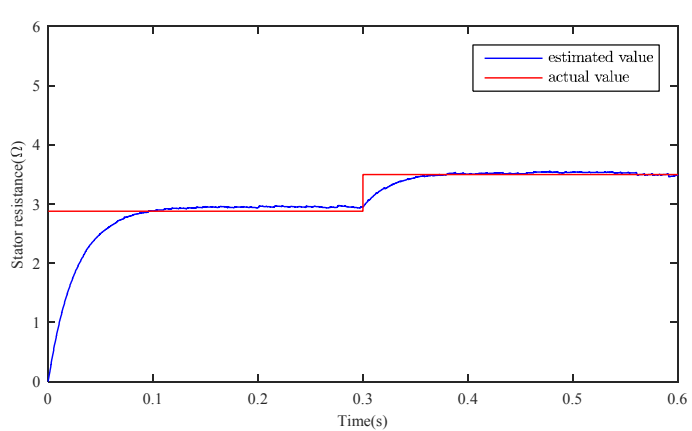

(c) Stator resistance

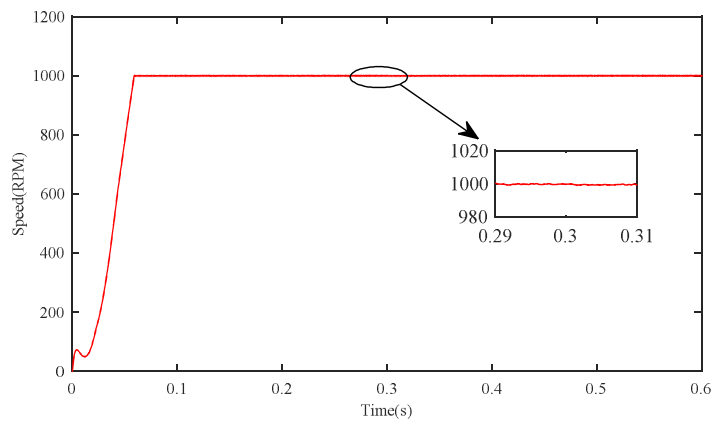

(d) Rotor speed response

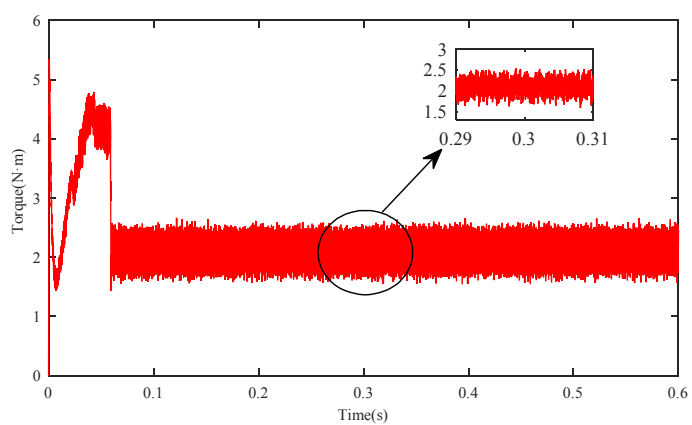

(e) Torque response

Fig.3. Dynamic response under variation of stator resistance

B. Dynamic response under the variation of load torque and stator resistance

Here, the load torque of $2 \mathrm{~N} \cdot \mathrm{m}$ is increased to $3 \mathrm{~N} \cdot \mathrm{m}$ at 0.2 seconds, and the stator resistance is changed from its nominal value $2.875 \Omega$ to $3.5 \Omega$ at 0.3 seconds. Fig.4 shows dynamic responses in terms of stator currents, stator resistance, rotor speed and torque when reference speed $\mathrm{n}^{*}$ is set to $1000 \mathrm{rpm}$.

From Figs.4(a)-4(c), it can be seen that, for designed ESO, its estimated $a$-axis and $c$-axis currents in $a b c$-frame rapidly track its actual value, and its estimated stator resistance follows its actual resistance change accurately. Figs. 4(d)-4(e) indicate that its speed and torque have strong immunity to not only load change but also stator resistance change, and the proposed ESO-based VC system has satisfactory control performance. 


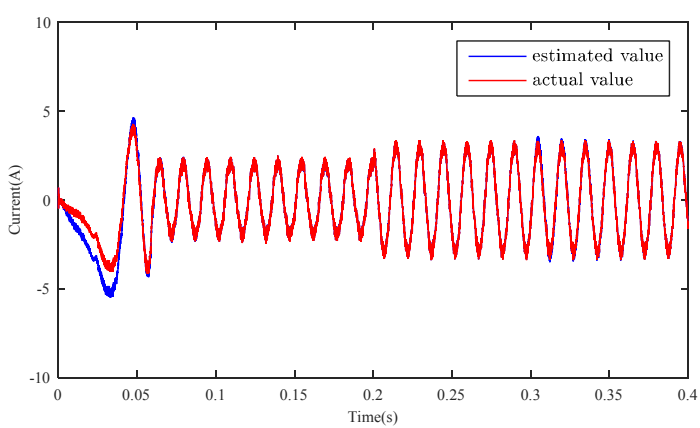

(a) $a$-axis stator current in $a b c$-frame

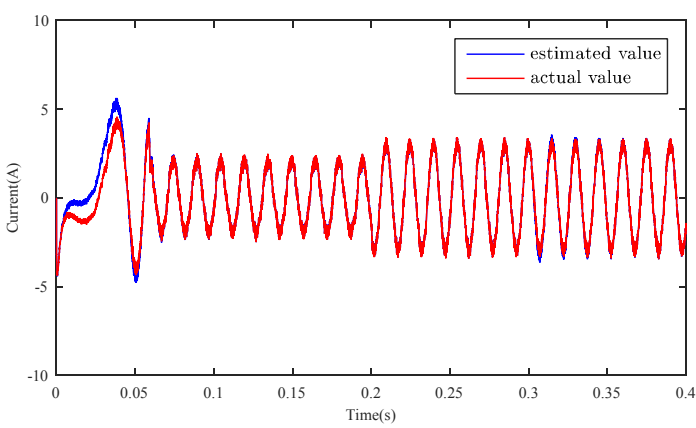

(b) $c$-axis stator current in $a b c$-frame

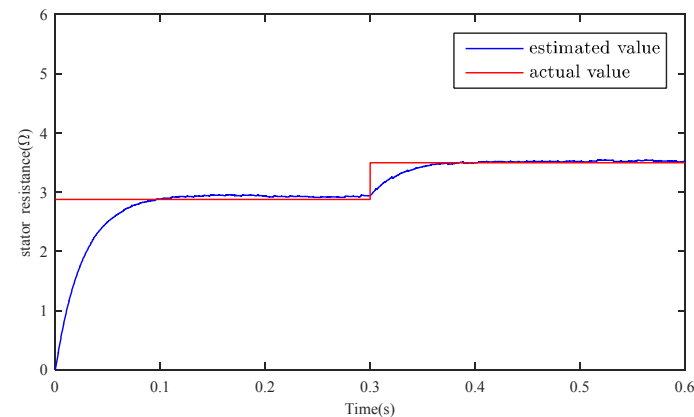

(c) Stator resistance

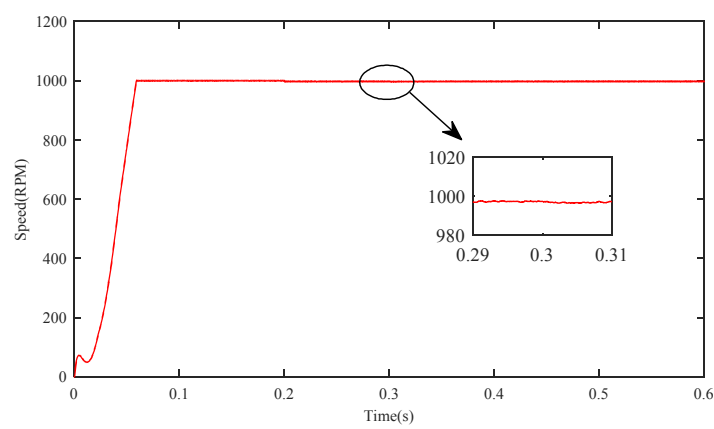

(d) Rotor speed response

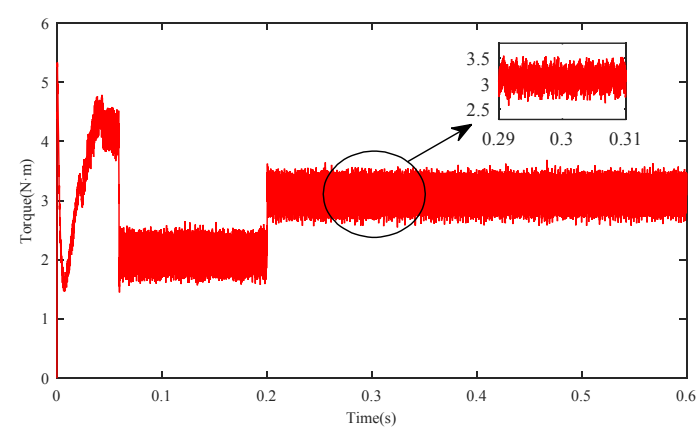

(e) Torque response

Fig.4. Dynamic response under variation of load and stator resistance
C. Dynamic response under the variation of load torque and stator resistance as well as reference speed

Here, reference speed $\mathrm{n}^{*}$ of $1000 \mathrm{rpm}$ is decreased to $600 \mathrm{rpm}$ at 0.2 seconds, stator resistance is changed from its nominal value $2.875 \Omega$ to $3.5 \Omega$ at 0.3 seconds and the load torque of $2 \mathrm{~N} \cdot \mathrm{m}$ is increased to $3 \mathrm{~N} \cdot \mathrm{m}$ at 0.4 seconds. Fig.5 shows dynamic responses in terms of stator currents, stator resistance, rotor speed and torque.

From Figs.5(a)-5(c), it can be seen that, for designed ESO, its estimated $a$-axis and $c$-axis currents in $a b c$-frame rapidly track its actual value, and its estimated stator resistance follows its actual resistance change accurately. Figs. 5(d)-5(e) demonstrate that except a sharp pulse of stator currents and torque caused by reference speed jump at 0.2 seconds, its speed and torque can rapidly adapt to both load variation and stator resistance change as well as reference speed change, and the proposed ESO-based VC system has satisfactory control performance.

Summarizing above simulation experiments, the following analysis results can be obtained

- The proposed observer can estimate the actual $a$-axis and $c$-axis currents as well as time-varying stator resistance rapidly and accurately.

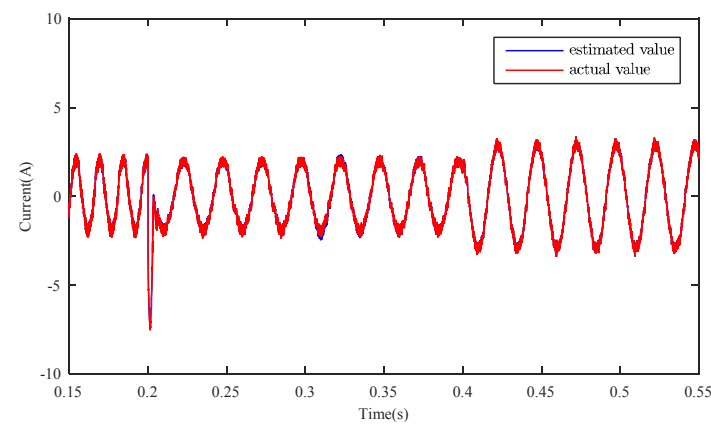

(a) $a$-axis stator current in $a b c$-fram

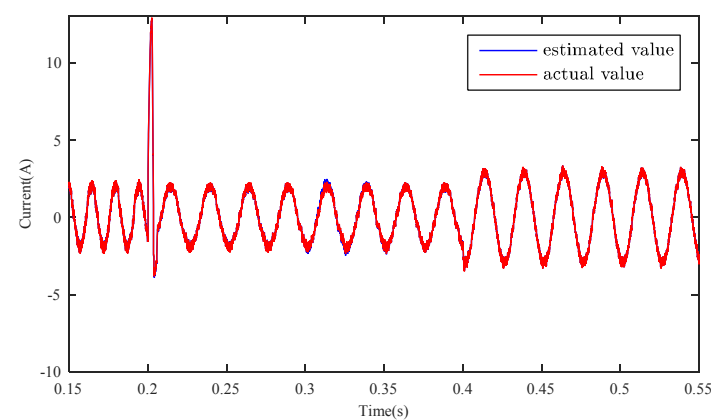

(b) $c$-axis stator current in $a b c$-fram

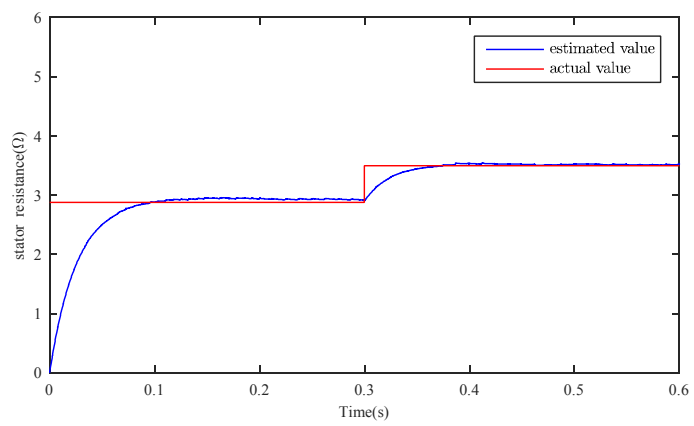

(c) Stator resistance 


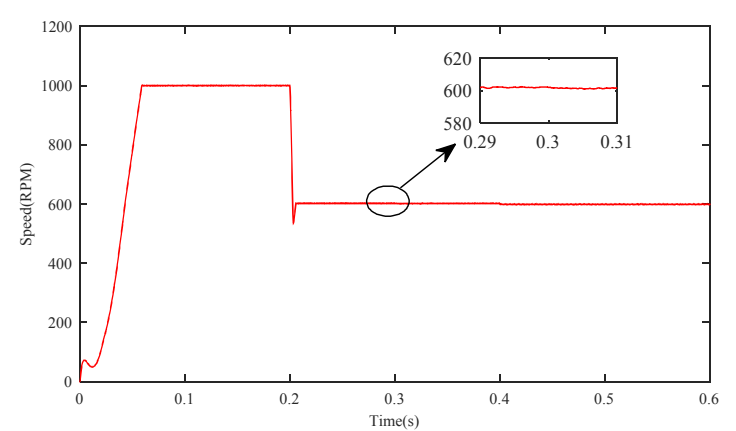

(d) Rotor speed response

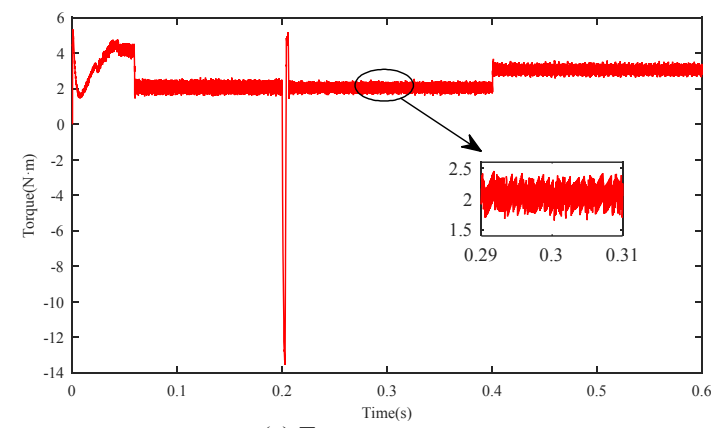

(e) Torque response

Fig.5. Dynamic response under variation of reference speed, stator resistance and load

- The designed ESO-based VC PMSM drive system has strong capable of accommodating the challenge of load variation and stator resistance change as well as reference speed change, and thus has satisfactory dynamical response behavior and strong robustness.

\section{CONCLUSIONS}

This paper has put forward a novel ESO-based VC scheme for three-phase PMSM drive system with only one phase current sensor. The designed ESO is capable of quickly and accurately estimating both the remaining two phase currents and time-varying stator resistance under the assumption that rotor speed and position are available for measurement, and meanwhile is capable of accommodating the challenge of load disturbance and speed change as well as reference speed change. In case of a phase current sensor failure, the proposed observer can be used as a virtual sensor and thus can be embedded into a fault resilient PMSM drive system. The designed ESO-based VC strategy can guarantee that PMSM drive system achieves satisfactory torque and speed control and strong robustness. Comprehensive simulation validates the feasibility and effectiveness of the proposed scheme.

\section{REFERENCES}

[1] G D. Chung, S. Sul. "Analysis and compensation of current measurement error in vector-controlled AC motor drives," IEEE Trans. Industrial Application, vol. 34, no. 2, pp. 340345, Mar/Apr. 1998.

[2] Y. S. Jeong, S. K. Sul, E. Schulz, et al. "Fault detection and fault-tolerant control of interior permanent-magnet motor drive system for electric vehicle," IEEE Trans. Industrial Application, vol. 41, no. 1, pp. 46-51. Jan. Feb. 2005.
[3] J. T. Boys. "Novel current sensor for PWM ac drives," In IEE Proceedings: Electric Power Applications, vol. 135, pp. 27-32, 1988.

[4] H. Y. Ma, K. Sun, Q. Wei, et al. "Phase current reconstruction for AC motor adjustable speed drives in the over modulation method," Journal of Tsinghua University, vol. 50, no. 11, pp. 1757-1761, 2010.

[5] Y. K. Gu, F. L. Ni, D. P. Yang, et al. "Switching-State Phase Shift Method for Three-Phase-Current Reconstruction With a Single DC-Link Current Sensor," IEEE Transactions on Industrial Electronics, vol. 58, no. 11, pp. 5186-5194, 2011.

[6] G. Lei, Y. G. Guo, J. G. Zhu, T. S. Wang, X. M. Chen, and K. R. Shao, "System level six sigma robust optimization of a drive system with PM transverse flux machine," IEEE Transactions on Magnetics, vol. 48, no. 2, pp. 923-926, 2012.

[7] Y. H. Cho, T. Labella, J. S. Lai. "A Three-Phase Current Reconstruction Strategy With Online Current Offset Compensation Using a Single Current Sensor," IEEE Transactions on Industrial Electronics, vol. 59, no. 7, pp. 2924-2933, 2012.

[8] Y. S. Lai, Y. K. Lin, C. W. Chen. "New hybrid pulse width modulation technique to reduce current distortion and extend current reconstruction range for a three-phase inverter using only DC-link sensor," IEEE Transactions on Power Electronics, vol. 28, no. 3, pp. 1331-1337, 2013.

[9] H. Lu, X. Cheng, W. Qu, et al. "A Three-Phase Current Reconstruction Technique Using Single DC Current Sensor Based on TSPWM," IEEE Transactions on Power Electronics, vol. 29,no. 3, pp. 1542-1550, 2014.

[10] S. C. Yang. "Saliency-Based Position Estimation of Permanent-Magnet Synchronous Machines Using SquareWave Voltage Injection With a Single Current Sensor," IEEE Transactions on Industry Applications, vol. 51, no. 2, pp. 1561-1571, 2015.

[11] Y.X. Xu, H. Yan, J.B. Zou, et al. "Zero Voltage Vector Sampling Method for PMSM Three-Phase Current Reconstruction Using Single Current Sensor," IEEE Transactions on Power Electronics, vol. 32,no. 5, pp. 3797-3807, 2016.

[12] L. Jarzebowicz, A. Opalinski, M. Cisek. "Improving Control Dynamics of PMSM Drive by Estimating ZeroDelay Current Value," Elektronika ir Elektrotechnika, vol. 21,no. 2, pp. 20-23, 2015.

[13] F. R. Salmasi, T. A. Najafabadi. "An adaptive observer with online rotor and stator resistance estimation for induction motors with one phase current sensor," IEEE Trans. on Energy Conversion, vol. 26, no. 3, pp. 959-966, 2011.

[14] Q. F. Teng, J. Y. Bai, J. G. Zhu, et al. "Current sensorless model predictive torque control based on adaptive backstepping observer for PMSM drives," WSEAS Transactions on systems, vol. 13, pp. 187-202, 2014.

[15] J.Q.Han, R. Zhang. "Error analysis of the second order ESO," Journal of Systems Science and Mathematical Sciences , 1999 , 19 (4):465 -471.

[16] J.Q.Han. "From PID technique to active disturbance rejection control technique," Control Engineering of China, vol.9, no.3, pp.13-18, 2002.

[17] Y.X.Su, C. H. Zheng, B. Y. "Duan. Automatic disturbances rejection controller for precise motion control of permanent-magnet synchronous motors," IEEE Transactions on Industrial Electronics, vol.52, no.3, pp.814-823, 2005. 